American Journal of Biochemistry and Biotechnology 5 (3): 137-141, 2009

ISSN 1553-3468

(C) 2009 Science Publications

\title{
The Supervirulence Plasmid pToK47 from Agrobacterium tumefaciens A281 Improves Transformation Efficiency of Hevea brasiliensis
}

\author{
${ }^{1}$ P. Arokiaraj, ${ }^{2}$ R. Leelawathy and ${ }^{2}$ H.Y. Yeang \\ ${ }^{1}$ Department of Biotechnology, Kulliyyah of Science, \\ International Islamic University of Malaysia, Jalan Istana, \\ Bandar Indra Mahkota, 25200 Kuantan, Malaysia \\ ${ }^{2}$ Rubber Research Institute of Malaysia, Malaysian Rubber Board, \\ 47000 Sungei Buloh, Selangor, Malaysia
}

\begin{abstract}
Problem statement: The present study investigates the ability of the pTok47 supervirulence plasmid form Agrobacterium tumefaciens A281 to enhance genetic transformation in Hevea brasiliensis. Approach: Hevea anther callus was transformed via Agrobacterium-mediated genetic transformation using two strains of Agrobacterium (GV2260 and GV3850) harboring the human serum albumin cDNA and the supervirulent plasmid pToK47 from Agrobacterium tumefaciens A281. The transformed callus was selected using kanamycin as the selection agent Results: The Agrobacterium strain GV2260 benefited from the presence of the supervirulence plasmid in giving a higher frequency of $7.4 \%$ transformed callus, $344.8 \%$ embryogenesis and $11.6 \%$ plantlet production compared to the corresponding strain on its own giving $0.9 \%$ transformed callus, $204.5 \%$ embryogenesis and $4.4 \%$ plantlet production. Similarly, Agrobacterium strain GV3850 conferred a higher frequency using the supervirulent plasmid, resulting in 3.5\% transformed callus, $138.5 \%$ embryogenesis and $3.5 \%$ plantlet production compared to the corresponding strain on its own giving $0.7 \%$ transformed callus, $137.5 \%$ embryogenesis and $9.0 \%$ plantlet production. These findings were confirmed by the Wilcoxon Signed Rank Test that compared the effectiveness of the supervirulence plasmid in increasing the rate of genetic transformation in the calli surviving in kanamycin growth medium for GV2260 $(\mathrm{p}<0.001)$ and for GV3850 ( $\mathrm{p}<0.05$ ). Conclusion: This study showed that both Agrobacterium strains benefited from the presence of the supervirulence plasmid in giving a higher frequency of transformed callus, embryoids and plantlets. These results suggest that a highly virulent binary vector system might prove especially useful in generating high frequency transformation of Hevea.
\end{abstract}

Key words: Hevea brasiliensis, Agrobacterium tumefaciens, supervirulence, callus, embryoids, human serum albumin, neomycinphosphotransferase II

\section{INTRODUCTION}

The main challenge with genetic transformation of tree species is achieving high transformation efficiency for desired clones or cultivars. In this respect, it is important to have an efficient tissue culture system to obtain plantlets from cells containing the transgene. In the case of Hevea brasiliensis (rubber tree), the highly embryogenic clone GL1 is routinely used as a vehicle for genetic transformation.

Agrobacterium tumefaciens harbors a tumorinducing plasmid ( $\mathrm{Ti}$ plasmid) and the region of $\mathrm{T}$ DNA within this plasmid encodes for the expression of the plant growth regulator genes for auxin and cytokinin, which leads to the formation of tumors in plant cells ${ }^{[1,2]}$. The $\mathrm{Ti}$ plasmid also harbors another important segment, the virulence (vir) region and this encodes most of the functions necessary for T-DNA transfer to plant cells ${ }^{[3]}$.

In A. tumefaciens A281 (the carrier of the plasmid pTiBo542) the tumors formed after infection with plant cells were larger, were early-appearing and the tumurogenesis applied to a wide range of plants, compared to other A. tumefaciens strains ${ }^{[4]}$. For the above reason, the plasmid pToK47 was constructed by subcloning a $15.8 \mathrm{~kb}$ fragment of pTiBo542 that carries the entire $\operatorname{vir} B$, virG and virC operons. When mobilized into Agrobacterium strains A348, A281, A208 and T37

Corresponding Author: P. Arokiaraj, Department of Biotechnology, Kulliyyah of Science,

International Islamic University of Malaysia, Jalan Istana, Bandar Indra Mahkota, 25200 Kuantan, Malaysia 
all the resulting strains displayed larger tumor formation compared with corresponding wild type strains $^{[4]}$.

Several publications have shown that transformation of previously recalcitrant species of monocotyledons (rice, corn and maize) can be accomplished through the use of disarmed A. tumefaciens strains to which additional copies of certain virulence genes were added $^{[5,6]}$ and also showed an improved procedure for production of white spruce using Agrobacterium containing the virulence regions from pToK $47^{[7,8]}$.

In the present investigation, an efficient transformation protocol for Hevea was developed using the supervirulence plasmid pToK47 containing virB, virC and virG genes from Agrobacterium tumefaciens A281.

\section{MATERIALS AND METHODS}

Agrobacterium strains and plasmid vectors: The binary vector pLGMR.HSA was constructed by inserting the expression cassette containing the 35SCaMV promoter, the multicloning sites and the CaMV Poly A tail from pJIT62 (Guerineau, France unpublished) into the polylinker of pBIN19 ${ }^{[9]}$ at $K p n I$ and $E c o R V$ sites. The gene segment coding for Human Serum Albumin (HSA) was amplified by Polymerase Chain Reaction (PCR). The PCR product (1.8 kb) was cloned into the SmaI site of pLGMR at the multicloning sites to yield the expression vector pLGMR. $\mathrm{HSA}^{[10]}$.

The plasmids, pLGMR.HSA and pToK47 ${ }^{[5]}$ were electroporated into electrocompetent cells of GV2260 ${ }^{[11]}$ and GV3850 ${ }^{[11]}$. The resultant strains containing the plasmids was reported by Arokiaraj and co-authors ${ }^{[10]}$.

Agrobacterium-mediated transformation: Hevea anther callus (clone GL1) was transformed using GV2260(pLGMR.HSA:pToK47)

or GV3850(pLGMR.HSA:pToK47) as described ${ }^{[12]}$. For transformation experiments, a total of 2332 anther callus derived from individual anthers of GL1 cultivar were immersed for $1 \mathrm{~min}$ in Agrobacterium suspension for the two strains with and without pToK47. A total of 16 individual experiments were performed with an equal number of anther callus ranging from 75-210. After immersion of the calli in an Agrobacterium suspension for $1 \mathrm{~min}$, the calli were blotted dry using sterile Whatman No 1 filter paper and then transferred to initiation medium ${ }^{[13]}$ for a co-cultivation period of 2 days. The calli were then transferred to fresh initiation medium containing cefotaxime (Duchefa, Holland) at
$300 \mu \mathrm{g} \mathrm{mL}^{-1}$ and ticarcillin (Duchefa, Holland) at 300 $\mu \mathrm{g} \mathrm{mL} \mathrm{L}^{-1}$ to eliminate Agrobacterium infection.

Selection of transformants and regeneration into plantlets: After 1 week without selection, calli were transferred to fresh initiation medium containing $50 \mu \mathrm{g} \mathrm{mL}^{-1}$ kanamycin. The calli were transferred to fresh initiation medium every 2 weeks and the selection on kanamycin was increased from $50-100 \mu \mathrm{g} \mathrm{mL}^{-1}$ in the third selection. The concentrations of cefotaxime and ticarcillin were reduced from 300-150 $\mathrm{g} \mathrm{mL}^{-1}$ and the finally to a concentration of $100 \mu \mathrm{g} \mathrm{mL}{ }^{-1}$ in the third selection. Calli that were kanamycin resistant was isolated and subcultured onto fresh initiation medium for 45-50 d, after which the calli were transferred to differentiation medium ${ }^{[13]}$ containing $100 \mu \mathrm{g} \mathrm{mL}^{-1}$ kanamycin for a period of 2 months. Kanamycinresistant embryoids were generated and transferred to developmental medium ${ }^{[13]}$ for plantlet production.

PCR determination of Hevea transformants: Primers for HSA and NPTII cDNA analysis in putative kanamycin-resistant callus were as follows: HSA: 5'atgaagtgggtaacctttatttcc-3' and 5' ttataagcctaaggcagcttgac-3' (positions 39-63 and 18691848) ${ }^{[14]}$; NPTII: 5' -gaggctattcggctatgactg-3' and 5'atcgggagcggcgataccgta-3' (positions 201-222 and 900$879)^{[15]}$. The presence of the inserted genes in putative callus and embryoids of Hevea was analyzed using routine PCR techniques ${ }^{[16]}$.

Statistical analysis: In data analysis, variation due to day to day effects were removed by pairing treatments with and without pToK47. As Gaussian distribution of the data was suspect, a nonparametric paired test, the Wilcoxon Matched Pairs Signed Rank Test, was used in statistical evaluation of the effectiveness of the supervirulence plasmid on transformed (i.e., kanamycin-resistant) calli and transformed embryos.

\section{RESULTS}

DNA analysis in putative transformants of Hevea: PCR analysis was used to detect the presence of NPTII and HSA in the kanamycin-resistant callus tissues. Genomic DNA from independently transformed and untransformed (control) tissues was subjected to PCR. Fig. 1 shows that the samples from transformed tissues gave the predicted DNA fragment bands of $0.7 \mathrm{~kb}$ for NPTII gene (lanes 3-8), Fig. 1a and $1.8 \mathrm{~kb}$ for HSA gene (lanes 3-8), Fig. 1b, whereas no amplification was detected in the sample from untransformed tissue. 


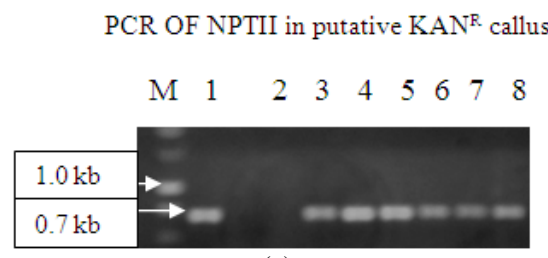

(a)

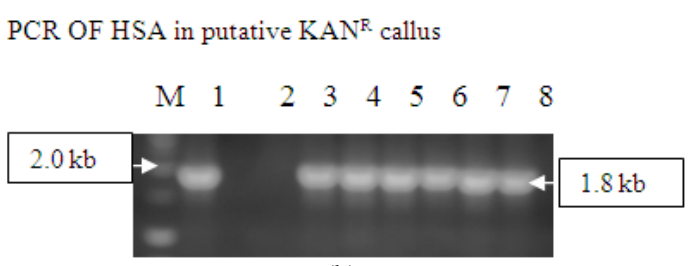

(b)

Fig. 1: PCR analysis of transformed callus tissues of Hevea was analyzed. DNA was amplified with specific primers for NPTII and HSA cDNA. (Lane M) $1 \mathrm{~kb}$ ladder; (1) pLGMR.HSA (positive control); (2) control plant; (3-8) putative transformants $\left(\mathrm{KAN}^{\mathrm{r}}\right.$ callus); Amplified fragments: 1a: NPTII $(0.7 \mathrm{~kb}), 1 \mathrm{~b}$ : HSA cDNA $(1.8 \mathrm{~kb})$

Table 1: Effect of the supervirulence plasmid in GV2260 on genetic transformation success

\begin{tabular}{lccl}
\hline & Without & With & $\begin{array}{l}\text { Statistical } \\
\text { Significance }\end{array}$ \\
\hline Calli cultures & 2332 & 2332 & \\
Transformed calli & 22 & 174 & $\mathrm{p}<0.001$ \\
Transformed embryoids & 45 & 600 & $\mathrm{p}<0.01$ \\
Transformed plantlets & 2 & 70 & $\mathrm{p}<0.01$ \\
\hline
\end{tabular}

\#: Wilsoxon's matched signed rank test

Southern analysis with the DIG HIGH-PRIME labeled NPTII and HSA probe showed a hybridization signal in the six transformed tissues analyzed (lanes 38) (Fig. 2a and b). These results show that sustained growth and development of the callus culture on kanamycin medium is a good indicator of successful genetic transformation.

Effectiveness of the supervirulence plasmid (pToK47) in GV2260 and GV3850 Agrobacterium strains: The most appropriate indicator of the effectiveness of the supervirulence plasmid in increasing the rate of genetic transformation is in the calli surviving in kanamycin growth medium. This is a direct measure of the rate of transfomation success. This finding was confirmed by the Wilcoxon Signed Rank Test that compared the results from each culture initiation day $(\mathrm{p}<0.001$ for GV2260 (Table 1) $\mathrm{p}<0.05$ for GV3850 (Table 2)).
Blots hybridized using NPTII cDNA

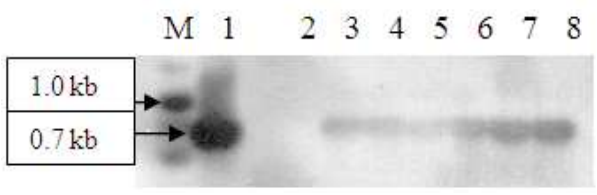

(a)

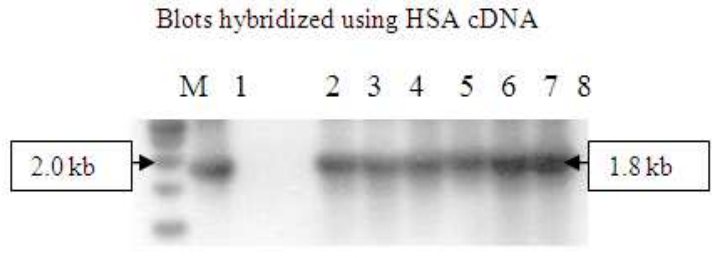

(b)

Fig. 2: Southern blot analysis of six putatively transformed and one untransformed (control) callus sample was analyzed. The NPTII cDNA, HSA cDNA and $1 \mathrm{~kb}$ ladder was labeled using the DIG HIGH-PRIME random labeling method. (Lane M): 1 kb ladder; (1): pLGMR.HSA (positive control); (2): control plant; (3-8): putative transformants $\left(\mathrm{KAN}^{\mathrm{r}}\right.$ callus); Hybridization signals was obtained for 2a: NPT II (0.7 kb) 2b: HSA (1.8 kb)

Table 2: Effect of the supervirulence plasmid in GV3850 on genetic transformation success

\begin{tabular}{lccl}
\hline & $\begin{array}{l}\text { Without } \\
\text { pToK47 }\end{array}$ & $\begin{array}{l}\text { With } \\
\text { pToK47 }\end{array}$ & $\begin{array}{l}\text { Statistical } \\
\text { Significance }^{\#}\end{array}$ \\
\hline Calli cultures & 2332 & 2332 & \\
Transformed calli & 16 & 83 & p $<0.05$ \\
Transformed embryoids & 22 & 115 & NS \\
Transformed plantlets & 2 & 4 & NS \\
\hline
\end{tabular}

\#: Wilsoxon's matched signed rank test; NS: Not Significant

While scorings of transformed embryoids or plantlets that develop subsequently might also reflect, to some extent, the role of the supervirulence plasmid, these indicators are not as accurate. Individual callus, once transformed with or without the help of the supervirulence plasmid are subsequently multiplied and the final number of transformed calli might not be exactly proportional to the number of original transformants. Moreover, some of transformed calli would be more successful than others in giving rise to multiple embryoids and plantlets later. Notwithstanding this, the numbers of embryoids and plantlets obtained from callus cultures with the supervirulence plasmid was higher in both GV2260 (Table 1) and GV3850 (Table 2), this advantage is statistically significant in GV2260 (Table 1). 


\section{CONCLUSION}

Clearly, Agrobacterium strains GV2260 and GV3850 containing an additional $15.8 \mathrm{~kb}$ fragment carrying extra copies of the virulence regions (virB, $\operatorname{virC}$ and $\operatorname{vir} G$ ) from the supervirulence plasmid, pToK47 gave a higher transformation frequency for Hevea as compared to controls. The advantage conferred by the supervirulence plasmid was more distinct with the GV2260 Agrobacterium strain then with the GV3850 strain. Efficient induction of Agrobacterium vir genes thus holds the key for increased rate of transformation in Hevea and certainly, increasing the expression of certain vir genes, at least in certain strains of Agrobacterium may increase their virulence and host range of infection. Thus, it is important to enhance our knowledge of the function and regulation of vir genes so that it may be possible to construct strains of Agrobacterium species that will be capable of transforming plants that are recalcitrant to infection by Agrobacterium.

\section{ACKNOWLEDGEMENT}

I would like to thank The Director General of The Malaysian Rubber Board and The Rector of the International Islamic University Malaysia for granting permission to publish this article.

\section{REFERENCES}

1. Chilton, M.D., M. Drummond, D. Merlo, D. Sciaky, A. Montoya, M. Gordon and E. Nester, 1977. Stable incorporation of plasmid DNA into higher plant cells: Molecular basis of crown gall tumurogenesis. Cell, 11: 263-271. http://www.ncbi.nlm.nih.gov/pubmed/890735

2. Akiyoshi, D., H. Klee, R. Amasino, E. Nester and M. Gordon, 1984. T-DNA of Agrobacterium tumefaciens encodes an enzyme of cytokinin biosynthesis. Proc. Natl. Acad. Sci. USA., 81: 5994-5998. http://www.ncbi.nlm.nih.gov/pubmed/6091129

3. Klee, H.J., F.F. White, V.N. Iyer, M.P. Gordon and E. Nester, 1983. Mutational analysis of the virulence region of an Agrobacterium tumefaciens Ti plasmid. J. Bacteriol., 153: 878-883. http://www.pubmedcentral.nih.gov/articlerender.fc gi? $\operatorname{artid}=221709$

4. Hood, E.E., G.L. Helmer, R.T. Fraley and M.D. Chilton, 1986. The hypervirulence of Agrobacterium tumefaciens A281 is encoded in a region of pTiBo542 outside of T-DNA. J. Bacteriol., 168: 1291-1301. http://www.pubmedcentral.nih.gov/articlerender.fc gi? artid=213636
5. Jin, S., T. Komari, M.P. Gordon and E.W. Nester, 1987. Genes responsible for supervirulence phenotype of Agrobacterium tumfaciens A281. J. Bacteriol., $\quad$ 169: 4417-4425. http://jb.asm.org/cgi/content/abstract/169/10/4417

6. Hansen, G., A. Das and M.D. Chilton, 1994. Constitutive expression of the virulence genes improves the efficiency of plant transformation by Agrobacterium. Proc. Natl. Acad. Sci. USA., 91: 7602-7607.

http://www.ncbi.nlm.nih.gov/pubmed/8052627

7. Rhodora, R.A. and K.H. Thomas, 1996. Agrobacterium tumefaciens mediated transformation of Japonica and India rice varieties. Planta, 199: 612-617. http://www.springerlink.com/content/v2361r77571 4175t/fulltext.pdf

8. Le, V.Q., J.B. Isles, M. Dusabenyagasami and F.M. Tremblay, 2001. An improved procedure for production of white spruce (picea gluca) transgenic plants using Agrobacterium tumefaciens. J. Exp. Bot., 52: 2089-2095. http://jxb.oxfordjournals.org/cgi/content/full/52/36 4/2089

9. Bevan, M., 1984. Binary agrobacterium vectors for plant transformation. Nucl. Acid. Res., 12: 8711-8721. http://www.ncbi.nlm.nih.gov/pubmed/6095209

10. Arokiaraj, P., F. Rueker, E. Oberymayr, A.R. Shamsul Bahri, J. Hafsah, D.C. Carter and H.Y. Yeang, 2002. Expression of human serum albumin in transgenic Hevea brasiliensis. J. Rubber Res., $\quad$ 5: 157-166. http://direct.bl.uk/bld/PlaceOrder.do?UIN=125807 100\&ETOC $=$ RN \& from $=$ searchengine

11. Deblaere, R., B. Bytebier, H. De Greve, F. Deboeck, J. Schell, M. Van Montagu and J. Leemans, 1985. Efficient octopine $\mathrm{Ti}$ plasmid vectors for Agrobacterium-mediated gene transfer to plants. Nucl. $\quad$ Acid. Res., 13: 4777-4788. http://www.ncbi.nlm.nih.gov/pubmed/4022773

12. Arokiaraj, P., H. Jones, H. Jaafar, S. Coomber and B.V. Charlwood, 1996. Agrobacterium mediated transformation of Hevea anther callus and their regeneration into plantlets. J. Nat. Rubber Res., 11: 77-87. http://direct.bl.uk/bld/PlaceOrder.do?UIN=018403 079\&ETOC $=$ RN\& from $=$ searchengine

13. Chen, Z., 1984. Rubber. In: Handbook of Plant Cell Culture: Crop Species, Sharp, W.R., D.A. Evans, P.V. Ammirato and Y. Yamada (Eds.). Macmillan, New York, ISBN: 10: 0070564744, pp: 546-571. 
14. Meloun, B., L. Moravek and V. Kostka, 1975. Complete amino acid sequence of human serum albumin. FEBS. Lett., 58: 134-137. http://www.ncbi.nlm.nih.gov/pubmed/1225573.

15. Beck, E., G. Ludwig, E.A. Auerswald, B. Reiss and H. Schaller, 1982. Nucleotide sequence and exact localization of the neomycin phosphotransferase gene from transposon Tn5. Gene, 19: 327-336. http://www.ncbi.nlm.nih.gov/pubmed/6295884
16. Hamill, J.D., S. Rounsley, A. Spencer, G. Todd and M.J.C. Rhodes, 1991. The use of polymerase chain reaction in plant transformation studies. Plant Cell Rep., 10 : 221-224. http://cat.inist.fr/?aModele=afficheN\&cpsidt=5064 737 